\title{
Improved lung function by means of retrograde flush in canine lung transplantation with non-heart-beating donors
}

\author{
Makio Hayama, MD \\ Hiroshi Date, MD \\ Takahiro Oto, MD \\ Motoi Aoe, MD \\ Akio Andou, MD \\ Nobuyoshi Shimizu, MD
}

From the Department of Cancer and Thoracic Surgery (Surgery II), Okayama University Graduate School of Medicine and Dentistry, Okayama, Japan.

Supported by the Research Grant for Cardiovascular Diseases (12C-6) from the Ministry of Health, Labor and Welfare, Japan.

Received for publication April 8, 2002; revisions requested June 13, 2002; revisions received July 18, 2002; accepted for publication Aug 6, 2002

Address for reprints: Hiroshi Date, MD, Department of Cancer and Thoracic Surgery (Surgery II), Okayama University Graduate School of Medicine and Dentistry, 2-5-1 Shikata Cho, Okayama 700-8558, Japan (E-mail: hdate@nigeka2.hospital.okayamau.ac.jp).

J Thorac Cardiovasc Surg 2003;125:901-6

Copyright (C) 2003 by The American Association for Thoracic Surgery

0022-5223/2003\$30.00+0

doi: $10.1067 / \mathrm{mtc} .2003 .296$
Objective: Use of lungs from non-heart-beating donors would increase the pulmonary donor pool. The aim of this study was to evaluate the effects of retrograde flush in canine lung transplantation from non-heart-beating donors.

Methods: Left lung transplantation was performed in 12 weight-matched pairs of dogs. Donors were killed without heparinization, left at room temperature for 2 hours, and then randomized into 2 groups. In group AF $(n=6)$ lung retrieval was performed after flushing the lung block with low potassium dextran glucose (50 $\mathrm{mL} / \mathrm{kg}$ ) solution through the pulmonary artery. In group $\mathrm{AF}+\mathrm{RF}(\mathrm{n}=6)$ additional retrograde flushing (low potassium dextran glucose, $25 \mathrm{~mL} / \mathrm{kg}$ ) was performed through the left atrium before retrieval. Flushed solution was sampled at intervals to measure hemoglobin concentrations. The lungs were preserved at $4^{\circ} \mathrm{C}$ for 2 hours, and the left lung was implanted to the recipient being subjected to a total ischemic time of 5 hours. After left lung transplantation, the right pulmonary artery and main bronchus were ligated. Lung function, including arterial blood gas and pulmonary hemodynamics, was measured for 3 hours. For lung function study, statistical analyses were performed by using 1-way analysis of variance with repeated measures.

Results: Group AF+RF had significantly better gas exchange and lower wet/dry weight ratio of the transplanted lung than group AF. Changes of hemoglobin concentration in the flushed solution indicated that additional retrograde flush could remove residual microthrombi after antegrade flush.

Conclusions: This study supports the theory that additional retrograde flush improves lung function after lung transplantation by removing residual pulmonary microthrombi in the lungs of non-heart-beating donors.

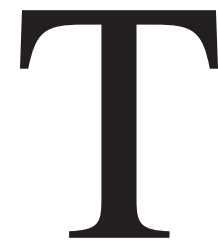

he critical shortage of lungs for transplantation has resulted in longer waiting times and annual increases in deaths on the lung transplant waiting list. One of the strategies to increase the size of the pulmonary donor pool might be to use lungs harvested from non-heartbeating donors. A recent striking report on successful human lung transplantation from non-heart beating donors by Steen and colleagues ${ }^{1}$ is gathering much attention.

In addition to the warm ischemic injury, intravascular pulmonary thrombi formation appears to be one of the major causes of reperfusion injury in lung transplantation from non-heart-beating donors. Retrograde flush through the pulmonary vein has been used in experimental ${ }^{2-5}$ and clinical ${ }^{6,7}$ lung transplantation and seems to offer better lung preservation with less edema and improved oxygen- 
TABLE 1. Characteristics of 2 experimental groups

\begin{tabular}{lccccrr}
\hline Group & $\begin{array}{c}\text { Donor weight } \\
(\mathbf{k g})\end{array}$ & $\begin{array}{c}\text { Recipient } \\
\text { weight }(\mathbf{k g})\end{array}$ & $\begin{array}{c}\text { Warm ischemic } \\
\text { time (min) }\end{array}$ & $\begin{array}{c}\text { Cold ischemic } \\
\text { time (min) }\end{array}$ & $\begin{array}{c}\text { Implantation } \\
\text { time (min) }\end{array}$ & $\begin{array}{c}\text { Total ischemic } \\
\text { time (min) }\end{array}$ \\
\hline $\mathrm{AF}(\mathrm{n}=6)$ & $12.8 \pm 3.9$ & $13.7 \pm 4.3$ & $120.8 \pm 1.9$ & $112.7 \pm 10.6$ & $67.7 \pm 10.4$ & $300.3 \pm 2.9$ \\
$\mathrm{AF}+\mathrm{RF}(\mathrm{n}=6)$ & $12.9 \pm 2.5$ & $13.2 \pm 2.8$ & $122.2 \pm 3.1$ & $112.7 \pm 6.3$ & $68.5 \pm 5.6$ & $302.0 \pm 3.4$ \\
\hline
\end{tabular}

All values are given as means \pm SEM.

TABLE 2. Assessment of lung and cardiac function of recipient

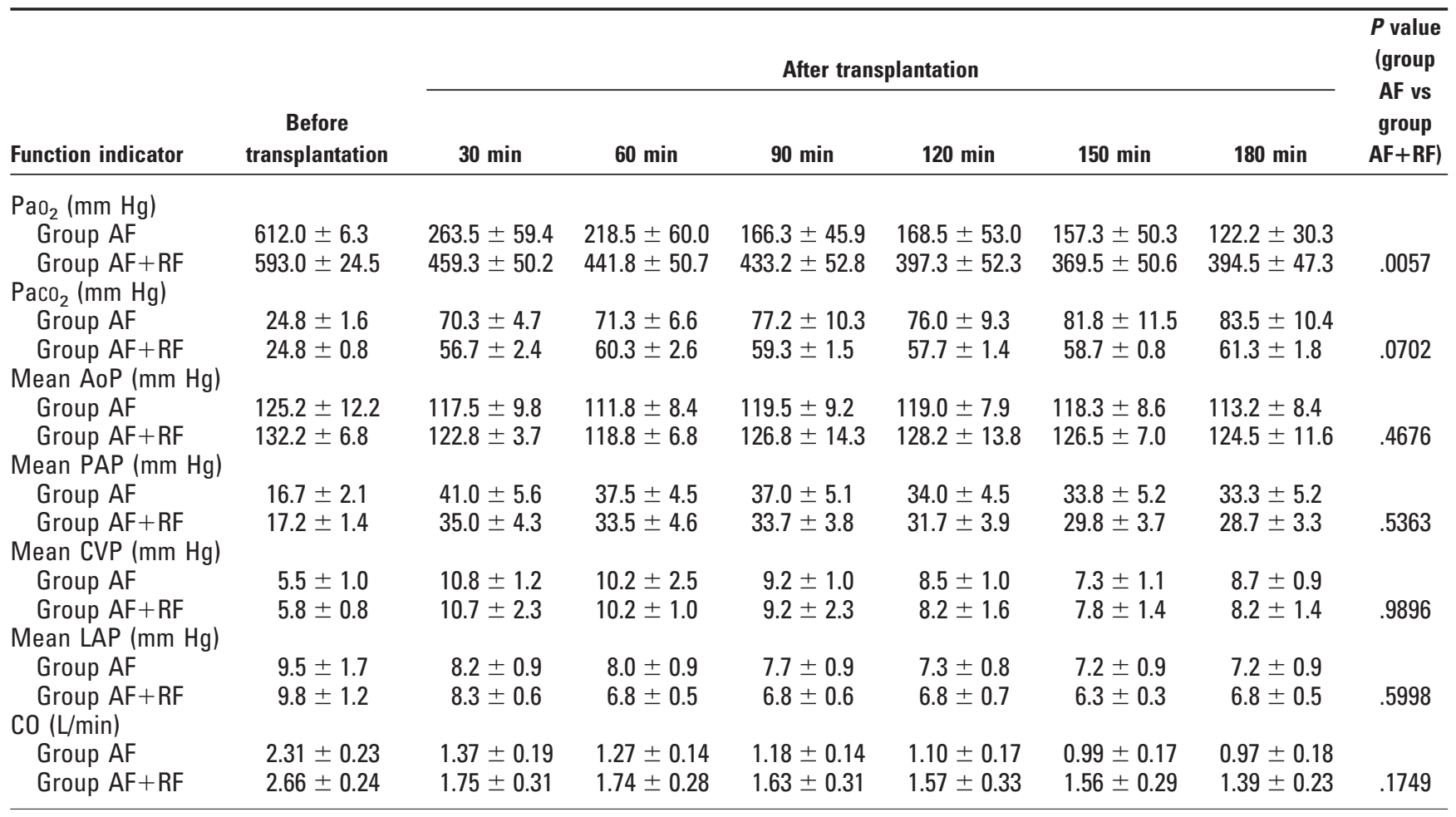

All values are given as means \pm SEM. Data after transplantation were obtained with the right pulmonary artery and the right main bronchus ligated.

ation. In this study we have evaluated the effects of retrograde flush in canine left single lung allotransplantation from non-heart-beating donors.

\section{Materials and Methods}

Twelve weight-matched pairs of adult mongrel dogs $(8.0-21.0 \mathrm{~kg})$ were used for left single lung allotransplantation. The donor dogs were premedicated with an intramuscular injection of ketamine hydrochloride $(10 \mathrm{mg} / \mathrm{kg})$ and atropine sulfate $(0.02 \mathrm{mg} / \mathrm{kg})$. Then the donor dogs were anesthetized by means of intravenous injection of thiopental sodium $(10 \mathrm{mg} / \mathrm{kg})$ and intubated. The donors were mechanically ventilated and killed by means of intravenous injection of potassium chloride without heparinization. After the mechanical ventilation was stopped, they were secured on the table in the supine position and left at room temperature for 2 hours. Then, through a median sternotomy, the main pulmonary artery and the left atrial appendage were incised. Postmortem thrombus in the pulmonary artery and left atrium was suctioned as much as possible. Mechanical ventilation was re-established at a tidal volume of $20 \mathrm{~mL} / \mathrm{kg}$, a respiratory rate of 15 breaths/min, and a positive end-expiratory pressure of $5 \mathrm{~cm}$ of $\mathrm{H}_{2} \mathrm{O}$. Through the main pulmonary artery, the lung block was antegradely perfused with $50 \mathrm{~mL} / \mathrm{kg}$ low potassium dextran glucose (LPDG) solution stored at $4{ }^{\circ} \mathrm{C}$ from a bag hung $50 \mathrm{~cm}$ above the chest. In group AF $(n=6)$ only antegrade flush was administered. In group AF+RF $(\mathrm{n}=6)$ an additional retrograde flush $(25 \mathrm{~mL} / \mathrm{kg})$ was administered through the left atrial appendage after ligation of the ascending aorta. Antegradely flushed solution was sampled from the left atrium at designed intervals (at one third, two thirds, and the end of the flush). Retrogradely flushed solution was sampled from the pulmonary artery at the beginning and at the end of the additional retrograde flush. Hemoglobin concentration was measured in each sample. We removed biopsy specimens from the right lung for histologic examination at the end of antegrade flush and at the end of additional retrograde flush. The heart-lung block, semi-inflated with $100 \%$ oxygen, was extracted, submerged in LPDG solution, and stored at $4^{\circ} \mathrm{C}$ for 2 hours.

The recipient dogs were sedated in the same manner as the donor dogs. General anesthesia was maintained with a 50:50 mixture of nitrous oxide and oxygen and $0.5 \%$ to $1.0 \%$ halothane. 
A 5F Swan-Ganz catheter was placed in the main pulmonary artery from the right femoral vein to measure pulmonary artery pressure (PAP), central venous pressure (CVP), and cardiac output (CO). A femoral artery line was inserted for measuring aortic pressure (AoP) and for arterial blood gas analysis. After the baseline measurement had been obtained, left pneumonectomy was performed through the left fifth intercostal space. The right pulmonary artery and the right main bronchus were encircled by 1-0 silk strings. A $5 \mathrm{~F}$ catheter was inserted into the left atrial appendage to measure left atrial pressure (LAP). On a back table, the left lung was trimmed from the donor heart-lung block, and left lung implantation was performed.

After transplantation, both lungs were ventilated with a tidal volume of $20 \mathrm{~mL} / \mathrm{kg}$ and a positive end-expiratory pressure of 5 $\mathrm{cm}$ of $\mathrm{H}_{2} \mathrm{O}$ at a rate of 15 breaths/min and an inspired oxygen concentration of 1.0. The right pulmonary artery and the right main bronchus were ligated 15 minutes after reperfusion, forcing the recipient to be dependent on the transplanted left lung for pulmonary function, and then the tidal volume was reduced to $10 \mathrm{~mL} / \mathrm{kg}$. The recipient dogs were observed for 3 hours, during which time AoP, PAP, CVP, and LAP values were continuously recorded. Measurement of $\mathrm{CO}$ and arterial blood gas analysis were performed at specific intervals $(30,60,90,120,150$, and 180 minutes after ligation of the right pulmonary artery and the right main bronchus). The chest was not closed, but the lung was loosely covered with normal saline solution-moistened sponges. After 3 hours of observation, the animals were killed with an overdose of intravenous injection of potassium chloride and thiopental sodium. The left upper and lower lobes were used to measure wet/dry (W/D) weight ratio, which was determined by measuring the weight difference in the specimen before and after being dried for about 2 weeks in an oven kept at $90^{\circ} \mathrm{C}$.

\section{Animal Care}

All dogs received human care in compliance with the "Principles of Laboratory Animal Care" formulated by the National Society for Medical Research and the "Guide for the Care and Use of Laboratory Animals" prepared by the Institute of Laboratory Animal Resources, National Research Council, and published by the National Academy Press, revised 1996.

\section{Statistics}

All values are given as means \pm SEM. One-way analysis of variance with repeated measures was used to determine whether an overall difference existed in lung function between the 2 groups during the 3-hour assessment period.

\section{Results}

For the 2 groups, the donor weight, recipient weight, warm ischemic time, cold ischemic time, implantation time, and total ischemic time were similar (Table 1). All 12 animals survived the operation and the 3 -hour assessment period.

\section{Pulmonary Function}

The results of gas exchange and the hemodynamics of the recipients during the 3-hour assessment period are shown in Table 2.

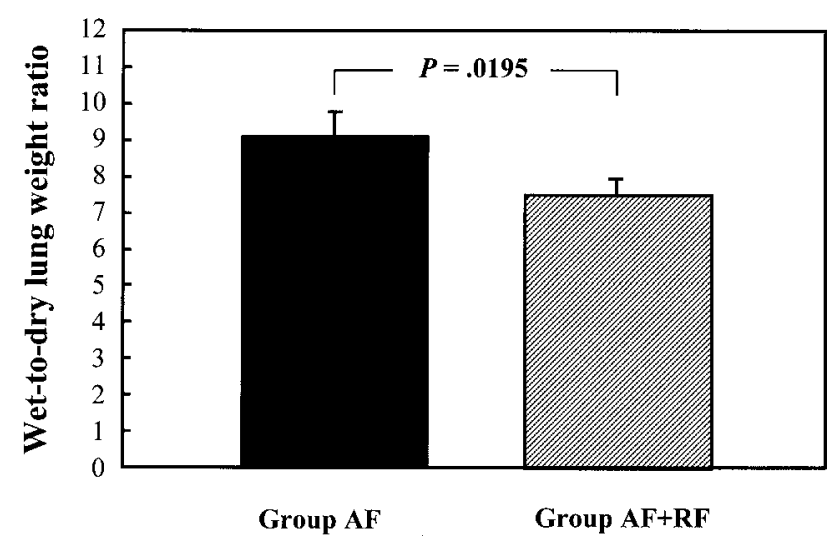

Figure 1. W/D lung weight ratio of transplanted lung after a 3-hour assessment period. The ratio was significantly lower in group $\mathrm{AF}+\mathrm{RF}(7.52 \pm 0.33)$ than in group AF $(8.98 \pm 0.41 ; P=.0195)$.

$\mathrm{PaO}_{2}$ was significantly better in group $\mathrm{AF}+\mathrm{RF}$ than in group $\mathrm{AF}(P=.0057)$. $\mathrm{PaCO}_{2}$ tended to be lower in group $\mathrm{AF}+\mathrm{RF}$ than in group $\mathrm{AF}(P=.0702)$.

Mean AoP and LAP values were stable during the experiment and were not significantly different between the 2 groups. Mean PAP and CVP values were significantly increased by means of ligation of the right pulmonary artery and bronchus $(P<.001)$ in both groups but were not significantly different between the 2 groups. CO was significantly decreased $(P<.001)$ by means of ligation of the right pulmonary artery and bronchus but were not significantly different between the 2 groups.

\section{W/D Ratio}

The W/D lung weight ratio in group $\mathrm{AF}+\mathrm{RF}$ was significantly lower than that in group AF (7.52 \pm 0.33 vs $8.98 \pm$ $0.41, P=.0195$, unpaired Student $t$ test; Figure 1).

\section{Macroscopic and Microscopic Findings}

After antegrade flushing, the donor lung surface looked patchy macroscopically (Figure 2, A). After additional retrograde pneumoplegia, the lung surface looked uniformly perfused in group $\mathrm{AF}+\mathrm{RF}$ (Figure 2,B).

Histologic studies of samples of lung parenchyma obtained after antegrade flushing demonstrated many residual blood cells or blood clots (Figure 3, A). These blood cells or blood clots were less observed after additional retrograde flushing in group AF+RF (Figure 3,B).

\section{Hemoglobin Concentration of Flushed Solution}

The change in the hemoglobin concentration of flushed solution in group AF+RF is shown in Figure 4. The hemoglobin concentration of antegradely flushed solution collected from the left atrium decreased gradually during antegrade flush. The hemoglobin concentration of retrogradely flushed solution collected from the pulmonary artery at the 

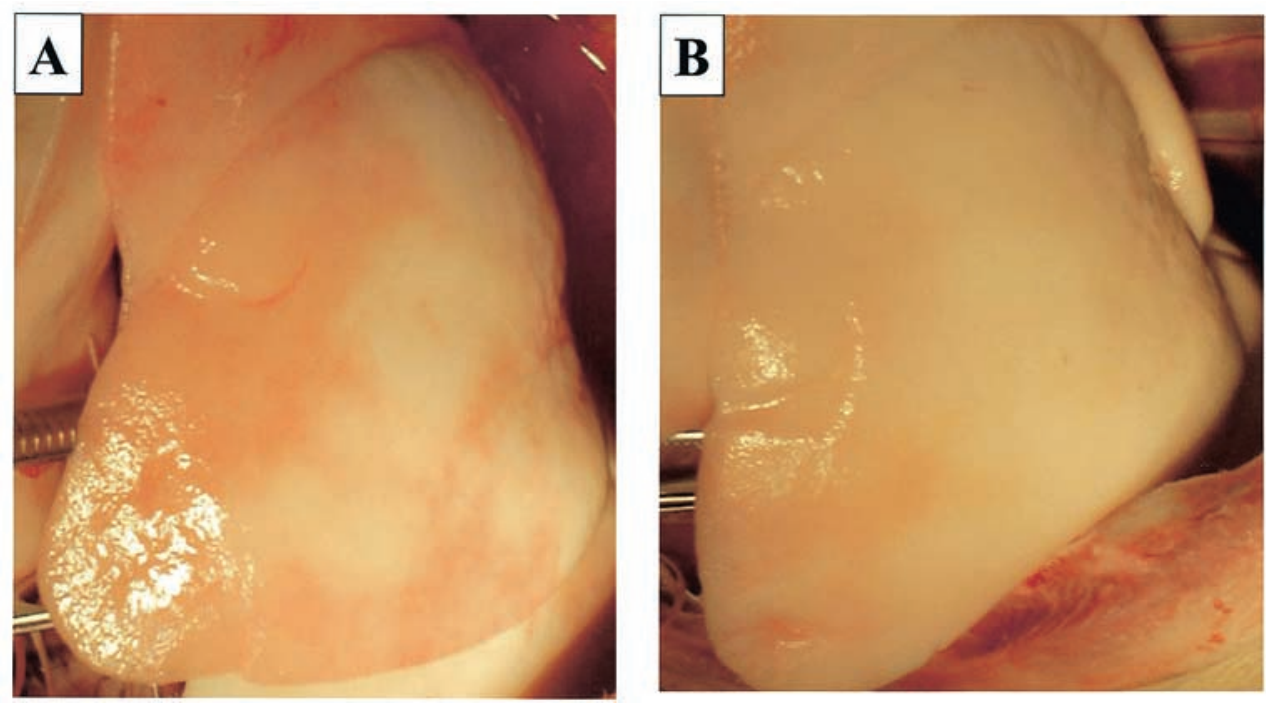

Figure 2. Macroscopic findings of donor lung in group AF+RF. A, End of antegrade flush. The lung surface looked patchy, indicating inhomogeneous perfusion. B, End of additional retrograde flush. The lung surface looked uniformly perfused, indicating that retrograde pneumoplegia could reach vascular segments that were not flushed by means of the forward route.

beginning of retrograde flush was significantly greater than that at the end of antegrade flush $(267.0 \pm 93.6$ vs $110.5 \pm$ $20.7 \mathrm{mg} / \mathrm{dL}$, paired Student $t$ test; $P=.0422$; Figure 4).

\section{Discussion}

Because the oxygen supply is interrupted during the preservation period, solid organs lose viability fairly rapidly, even during cold ischemia, as a result of anaerobic metabolism. The lung is the only organ that can be preserved with a ready supply of oxygen through the airway. ${ }^{8}$ Lung transplantation from non-heart-beating donors is based on the notion that pulmonary cellular elements might remain viable by using the oxygen in the alveoli for a certain period at warm temperature, even after cessation of circulation. Several strategies have been developed in an attempt to reduce warm ischemia-reperfusion injury (eg, oxygen radical scavengers, ${ }^{9}$ topical cooling, ${ }^{10,11}$ ventilating lungs, ${ }^{12}$ and inhaled nitric oxide ${ }^{13,14}$ ).

In addition to warm ischemic injury, microthrombi formation appears to be one of the major detrimental factors in lung transplantation from non-heart-beating donors, in which lungs are essentially preserved with warm whole blood. Microthrombi formation would result in an increase of intrapulmonary shunt, leading to hypoxia. Associated high precapillary pressure would further enhance poor gas exchange caused by lung edema. Eagan and coworkers ${ }^{15}$ demonstrated that a safe period of ischemia for the lung at normothermia is less than 2 hours without heparinization. Ulicny and colleagues ${ }^{12}$ demonstrated that the acceptable warm ischemic time could be extended to 4 hours when the lungs were fully heparinized before cardiac arrest and kept ventilated after death. For the concept of lung transplantation from non-heart-beating donors to be practical, it would be difficult to administer any pretreatment to the donor before death. In fact, heparinizing the donor for the purpose of organ donation is strictly restricted in Japan.

Then how do we deal with microthrombi in the lungs of non-heart-beating donors without pretreatment? There are several potential methods. Steen and associates ${ }^{1}$ administered heparin into a central venous catheter 10 minutes after declaration of death followed by 20 chest compressions in their successful human lung transplantation from a nonheart-beating donor. Microthrombi formation might be prevented with this method; however, it would be essential to administer heparin shortly after cardiac arrest. Our group has demonstrated that fibrinolytic drugs, such as urokinase ${ }^{16}$ or recombinant tissue-type plasminogen activator, ${ }^{17}$ improve lung function when they are administered into the lungs of non-heart-beating donors at 2 hours after cardiac arrest. We hypothesized that mechanical washout of preexisting pulmonary microthrombi by means of retrograde flush would improve lung function in lung transplantation from non-heart-beating donors.

Retrograde flush through the pulmonary vein or the left atrium has been used in experimental ${ }^{2-5}$ and clinical ${ }^{6,7}$ lung transplantation and seems to offer better lung preservation with less edema and improved oxygenation. Chen and coworkers ${ }^{2}$ simply compared antegrade flush and retrograde flush in canine left lung cold preservation for 6 hours and found that retrograde flush was superior in terms of gas 

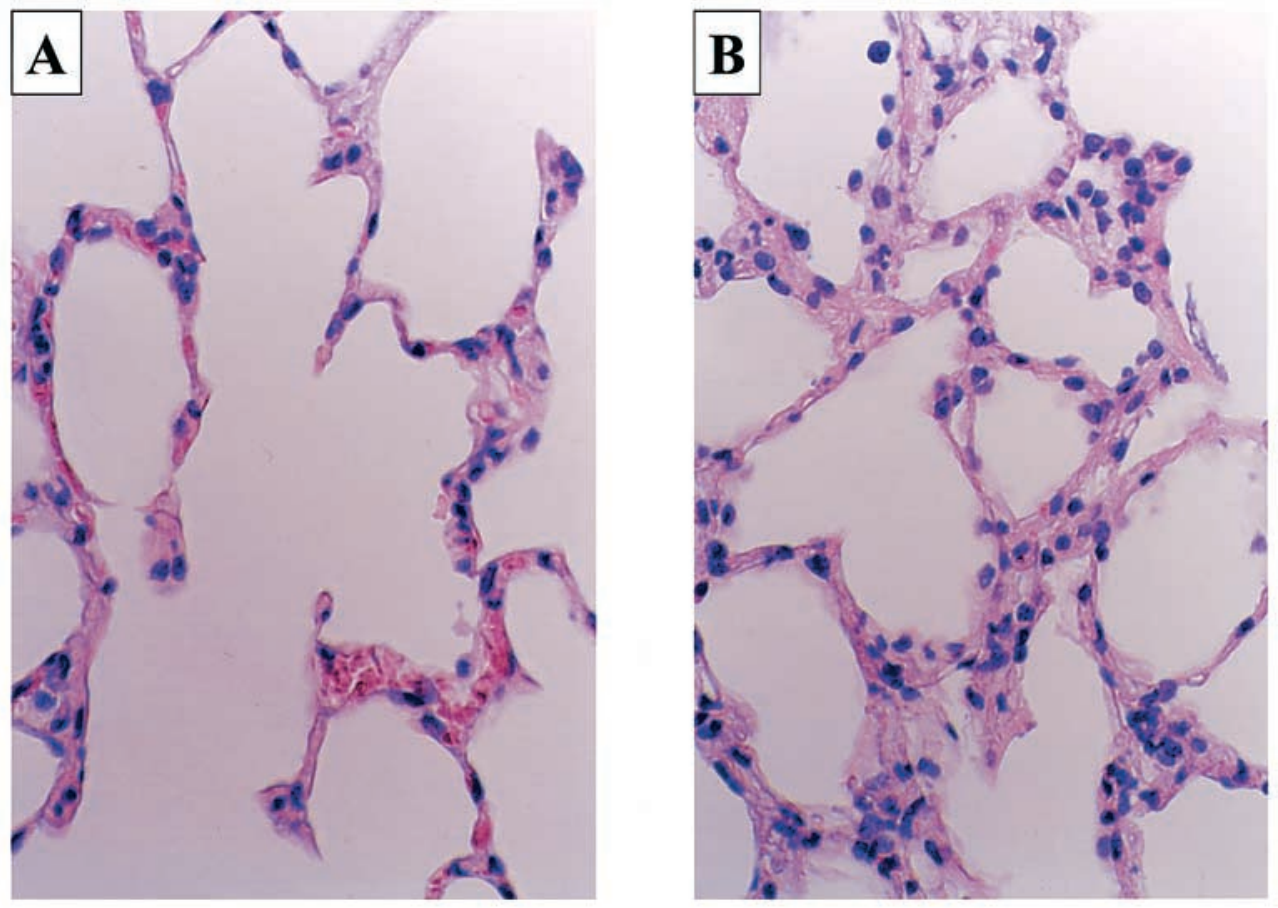

Figure 3. Histologic studies of samples of donor lung parenchyma in group AF+RF. (Hematoxylin and eosin stain; original magnification $100 \times$.) A, End of antegrade flush. Many residual blood cells or blood clots were observed in the capillary. B, End of additional retrograde flush. These blood cells or blood clots were less observed, indicating that retrograde pneumoplegia could reach a vascular segment that was not flushed by means of the forward route.

exchange and airway pressure. Baretti and colleagues ${ }^{3}$ showed that retrograde flush of pneumoplegic solution improved flow to distal trachea and bronchi without prostacyclin compared with antegrade flush. This study suggested that retrograde pneumoplegia has the advantage of flushing the bronchial circulation through the bronchopulmonary anastomoses, enhancing airway protection. Strüber and associates $^{4}$ reported that the disturbance of surfactant function was less pronounced in the retrograde flush group than in the antegrade flush group. A clinical advantage of retrograde flush was demonstrated by Venuta and coworkers ${ }^{7}$ in their human lung transplant program. They performed antegrade flushing at the time of retrieval, and additional retrograde flushing through the pulmonary veins was performed at the back table before implantation.

In the present study it was clearly shown that additional retrograde flush improved gas exchange and resulted in less edema, as demonstrated by W/D lung weight ratio. The mechanical washout of pre-existing pulmonary microthrombi by means of retrograde flush was observed macroscopically (Figure 2, $A$ and $B$ ) and microscopically (Figure $3, A$ and $B$ ). This phenomenon was further confirmed by the changes of hemoglobin concentration in the flushed solution (Figure 4). These results strongly suggested that there were

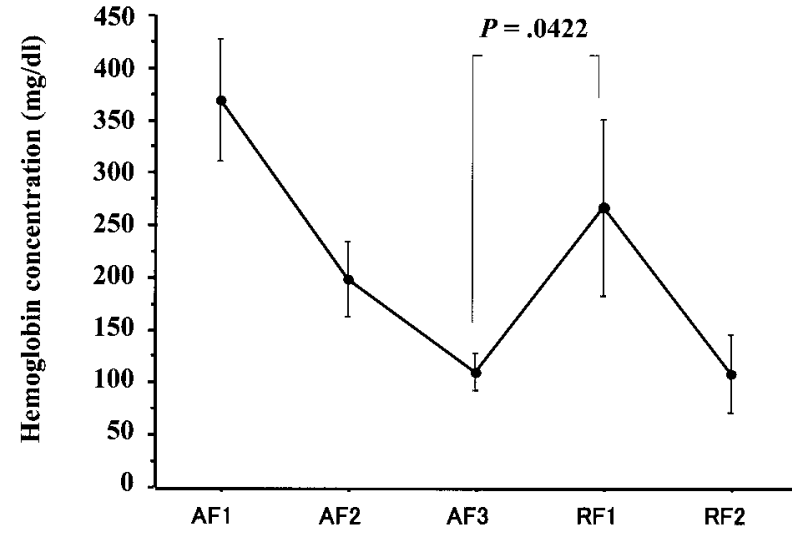

Figure 4. Change in hemoglobin concentration of flushed solution in group $A F+R F$. The hemoglobin concentration was significantly higher at the beginning of retrograde flush $(267.0 \pm 41.2 \mathrm{mg} / \mathrm{dL})$ than at the end of antegrade flush $(110.5 \pm 20.7 \mathrm{mg} / \mathrm{dL} ; P=.0422)$. $A F 1$, One third of antegrade flush; $A F 2$, two thirds of antegrade flush; $A F 3$, end of antegrade flush; $R F 1$, beginning of retrograde flush; $R F 2$, end of retrograde flush.

some residual microthrombi wedged in the precapillary area after antegrade flush, and they were removed by the additional retrograde flush. Luh and coworkers ${ }^{5}$ also reported 
that the retrograde flush might be beneficial to the protection of the non-heart-beating donor lung grafts at an early reperfusion period in their experimental study. However, in the study by Luh and coworkers, the lungs were kept ventilated after cardiac arrest. For the concept of lung transplantation from non-heart-beating donors to be practical, we did not administer any pretreatment to the donor before death and for 2 hours after death. The excellent lung function demonstrated in group AF+RF in this study by using a cadaver lung left at room temperature for 2 hours without heparinization and preserved with LPDG solution for 2 hours (total ischemic time of 5 hours, including implantation time) is very encouraging.

We acknowledge the expert technical assistance of Tetsuo Kawakami and the statistical advice of Richard B. Schuessler, $\mathrm{PhD}$.

\section{References}

1. Steen S, Sjöberg T, Pierre L, Liao Q, Eriksson L, Algotsson L. Transplantation of lungs from a non-heart-beating donor. Lancet. 2001;357:825-9.

2. Chen CZ, Gallagher RC, Ardery P, Dyckman W, Low HBC. Retrograde versus antegrade flush in canine left lung preservation for six hours. J Heart Lung Transplant. 1996;15:395-403.

3. Baretti R, Bitu-Moreno J, Beyersdorf F, Matheis G, Francischetti, Kreitmayr B. Distribution of lung preservation solutions in parenchyma and airways: influence of atelectasis and route of delivery. J Heart Lung Transplant. 1995;14:80-91.

4. Strüber M, Hohlfeld JM, Warnecke G, et al. Surfactant function in lung transplantation after 24 hours of ischemia: advantage of retrograde flush perfusion for preservation. $J$ Thorac Cardiovasc Surg. 2002;123:98-103.
5. Luh SP, Tsai CC, Shau WY, et al. The effect of inhaled nitric oxide, gabexate mesilate, and retrograde flush in the lung graft from nonheart beating minipig donors. Transplantation. 2000;69:2019-27.

6. Varela A, Cordoba M, Serrano-Fiz S, et al. Early lung allograft function after retrograde and antegrade preservation. $J$ Thorac Cardiovasc Surg. 1997;114:1119-20.

7. Venuta F, Rendina EA, Bufi M, et al. Preimplantation retrograde pneumoplegia in clinical lung transplantation. $J$ Thorac Cardiovasc Surg. 1999;118:107-14.

8. Date H, Matsumura A, Manchester JK, et al. Evaluation of lung metabolism during successful twenty-four-hour canine lung preservation. J Thorac Cardiovasc Surg. 1993;105:480-91.

9. Roberts CS, Hennington MH, D'Armini, Griffith PK, Lemasters JJ, Eagan TM. Donor lungs from ventilated cadavers: impact of a free radical scavenger. J Heart Lung Transplant. 1996;15:275-82.

10. Steen S, Ingemansson R, Budrikis A, Bolys R, Roscher R, Sjöberg T. Successful transplantation of lungs topically cooled in the non-heartbeating donor for 6 hours. Ann Thorac Surg. 1997;63:345-51.

11. Wierup P, Bolys R, Steen S. Gas exchange function one month after transplantation of lungs topically cooled for 2 hours in the non-heartbeating cadaver after failed resuscitation. J Heart Lung Transplant. 1999;18:133-8.

12. Ulicny KS Jr, Egan TM, Lambert CJ Jr, Reddick R, Wilcox BR. Cadaver lung donors: effect of preharvest ventilation on graft function. Ann Thorac Surg. 1993;55:1185-91.

13. Takashima S, Date H, Aoe M, Yamashita M, Andou A, Shimizu N. Effects of inhaled nitric oxide in canine lung transplantation from non-heart-beating donor. Jpn J Thorac Cardiovasc Surg. 1998;46: 657-63.

14. Takashima S, Date H, Aoe M, Yamashita M, Andou A, Shimizu N. Short-term inhaled nitric oxide in canine lung transplantation from non-heart-beating donor. Ann Thorac Surg. 2000;70:1679-83.

15. Egan TM, Lambert CJ Jr, Reddick R, Ulicny KS Jr, Keagy BA, Wilcox BR. A strategy to increase the donor pool: use of cadaver lungs for transplantation. Ann Thorac Surg. 1991;52:1113-21.

16. Umemori Y, Date H, Uno k, Aoe M, Ando A, Shimizu N. Improved lung function by urokinase infusion in canine lung transplantation using non-heart-beating donors. Ann Thorac Surg. 1995;47:329-37.

17. Akasaka S, Nishi H, Aoe M, Date H, Andou A, Shimizu N. The effects of recombinant tissue-type plasminogen activator (rt-PA) on canine cadaver lung transplantation. Surg Today. 1999;29:747-54. 